\title{
Pastoral Ministry in Unsettled Times: A Qualitative Study of the Experiences of Clergy During the COVID-19 Pandemic
}

\author{
Erin F. Johnston ${ }^{1}$ D $\cdot$ David E. Eagle $^{1}$ D $\cdot$ Jennifer Headley ${ }^{1}$ D $\cdot$ Anna Holleman $^{2} \mathbb{D}$
}

Received: 11 May 2021 / Accepted: 5 July 2021 / Published online: 6 August 2021

(c) Religious Research Association, Inc. 2021

\begin{abstract}
Background COVID-19 and its associated restrictions around in-person gatherings have created unprecedented challenges for religious congregations and those who lead them. While several surveys have attempted to describe how pastors and congregations responded to COVID-19, these provide a relatively thin picture of how COVID-19 is impacting religious life. There is scant qualitative data describing the lived reality of religious leaders and communities during the pandemic.

Purpose and methods This paper provides a more detailed look at how pastors and congregations experienced and responded to COVID-19 and its associated restrictions in the early period of the pandemic. To do so, we draw from 26 in-depth interviews with church-appointed United Methodist pastors conducted between June and August 2020. Pastors were asked to describe how their ministry changed as a result of COVID-19 and interviews were analyzed using applied thematic analysis approaches to identify the most common emergent themes.

Results Pastors reported that COVID-19 fundamentally unsettled routine ways of doing ministry. This disruption generated both challenges and opportunities for clergy and their congregations. In the findings, we describe how clergy responded in key areas of ministry-worship and pastoral care-and analyze how the pandemic is (re)shaping the way that clergy understood their role as pastors and envisioned the future of the Church. We argue for the value of examining the pandemic as an "unsettled" cultural period (Swidler 1986) in which religious leaders found creative ways to (re)do ministry in the context of social distancing. Rather than starting from scratch, we found that pastors drew from and modified existing symbolic and practical tools to fit pandemic-related constraints on religious life. Notably, however, we found that "redoing" ministry was easier and more effective in some areas (worship) than others (pastoral care).
\end{abstract}

Conclusions and Implications The impact of COVID-19 on pastors and congregations is complex and not fully captured by survey research. This study provides a baseline for investigating similarities and differences in the responses of pastors within and across denominations and traditions. It also provides a baseline for

Extended author information available on the last page of the article 
assessing whether changes in ministry implemented during the early stages of the pandemic remain in place in the post-COVID world.

Keywords Clergy $\cdot$ COVID-19 $\cdot$ Ministry $\cdot$ Worship $\cdot$ Pastoral care $\cdot$ Unsettled times $\cdot$ Congregational culture

\section{Introduction}

COVID-19 and its associated restrictions around in-person gatherings created unprecedented challenges for religious congregations and those who lead them. In March 2020, public health officials across the country ordered religious organizations to limit in-person activities and move worship and other services online. This mandate disrupted one of the most fundamental activities of religious congregations-bringing people together for corporate worship (Chaves 2004). As a result, often in the span of a few days, clergy were forced to adapt the practices of their religious communities to public-health restrictions (Sulkowski and Ignatowski 2020) and denominational guidelines. While several surveys have attempted to describe how pastors and congregations responded (Lifeway Research 2020; Manion and Strandberg 2020; O’Brien 2020; Seabright and Raiber 2020; Sulkowski and Ignatowski 2020), these provide a relatively thin picture of how COVID-19 is impacting the work of pastoral ministry and congregational culture. Our aim is to provide a more detailed and nuanced look at how pastors and congregations experienced and responded to COVID-19 and its associated restrictions during the early period of the pandemic.

To do so, we draw from 26 in-depth interviews with church-appointed United Methodist pastors conducted between June and August 2020 in which we asked pastors to describe how, if at all, their ministry changed in the wake of COVID-19. The majority of clergy we spoke with described the pandemic as profoundly disruptive of ministry-as-usual, upending their usual habits, practices, and routines in relation to core aspects of their work such as worship services and pastoral care. We found this disruption generated both challenges and opportunities for clergy and their congregations. In the early period, pastors scrambled to create and implement new forms of practice and strategies for connecting with congregants. This required considerable time and energy but also allowed for creativity and innovation. By forcing them to adapt ministry to public health restrictions, the pandemic has also pushed some clergy to rethink their role and the role of the Church.

Based on our findings, we propose the value of examining the pandemic as an unsettled cultural period (Swidler 1986, 2013) ${ }^{1}$-a moment in which cultural ideas and practices are in flux-for religious institutions and communities. Swidler (1986, 2013) argues that culture functions differently in settled versus unsettled times. In settled times, "culture is intimately integrated with action ... culture and structural

\footnotetext{
1 Recent research on the impact of COVID-19 in other social fields has also suggested the value of this framework (Goode, Stroup, and Gaufman 2020; Shepherd et al. 2020).
} 
circumstance seem to reinforce each other" (Swidler 1986: 278). As a result, people rarely think consciously about their actions. However, unsettled moments raise previously unconsidered practices to the level of conscious thought and prompt actors to reconsider the status quo, and, if necessary, develop new strategies for action (see Swidler 1986: 278-280; Swidler 2013: 99-103). During unsettled periods, religious leaders, as cultural producers, "refashion aspects of their own religious cultures ... they create new means to old, or new, cultural ends" (Regnerus and Smith 1998: 1351). Swidler's analytic framework foregrounds the pandemic's potential to change pastoral ministry and congregational culture by forcing pastors to create new strategies of action (new means) and possibly, by prompting clergy to more fundamentally rethink the meaning of worship, ministry, or the Church (new ends). This paper provides an illustration of the value of this framework for making sense of the pandemic's impact on pastors and congregations. In the discussion, we highlight key take-aways from our research and identify questions for future research.

\section{Data and Methods}

This study is based on in-depth, semi-structured interviews with 26 churchappointed United Methodist pastors in one of the two Annual Conferences in North Carolina. ${ }^{2}$ The United Methodist Church (UMC) is a particularly useful case study for several reasons. First, it is the third-largest denomination in the United States, involving nearly 6.5 million members, 30,543 churches, and 38,308 clergy (General Council on Finance and Administration of the United Methodist Church 2018) and representing $9 \%$ of all religious congregations in the country (Chaves et al. 2020). Second, UMC denominational leaders encouraged congregations to abide by public health guidelines and UMC congregations, like most churches in the US (Lifeway Research 2020; Seabright and Raiber 2020), generally did so. In May 2020, a federal court overturned a North Carolina executive order that limited indoor religious gatherings, meaning congregations were allowed to set their own COVID protocols (Bridges 2020). The two UMC conferences in the state did not issue direct orders, but instead issued recommendations to congregations to honor public health guidelines encouraging mask-wearing and social distancing (UMC NC Conference 2020b; UMC Western NC Conference 2020). As a result, pastors had considerable leeway to modify practices in line with their congregation's specific needs, preferences, and available resources. Clergy, as leaders of their congregations, were typically responsible for making final decisions regarding whether and how to gather; their responses provide important insights into how COVID-19 restructured congregational life. By focusing on pastors in one denomination in a single state, we were able to identify similarities and differences in how pastors under similar guidelines responded. We opted for in-depth interviews as the primary method of data collection. Interviews provided a more detailed picture of COVID-19's impact on clergy

\footnotetext{
${ }^{2}$ In North Carolina, the United Methodist Church is organized into two Annual Conferences with a combined membership of almost 500,000 people, 2300 churches, and 1800 clergy.
} 
and congregations than would be possible using survey data, particularly during such a dynamic and evolving time.

Participants were 26 UMC pastors currently appointed to serve 32 congregations; they were interviewed between June and August, 2020. Participants had previously responded to the 2019 Clergy Health Initiative Statewide Survey of United Methodist Clergy, a longitudinal survey of all UMC clergy in North Carolina with a response rate of $73 \%(n=1454)$. To capture variation across the career-span, we purposively sampled three different groups of survey respondents based on number of years in ministry: early career (five or fewer years), mid-career (six to 19 years), and later career (20 or more years). Within each career stage, we ensured that nonwhite pastors were represented in the respondent pool in proportion to their overall presence in the state. A total of 61 potential participants were identified for recruitment and invited by email to participate in the study. Potential participants were contacted a maximum of four times before being removed. Of the 35 participants not interviewed, four declined to participate, one was ineligible, one was unable to be scheduled, and the remaining 27 did not reply or respond.

Our sample was $88 \%$ white, $50 \%$ male, and, on average, 44 years old. Ten participants were early career, nine were mid-carrier, and seven were late career. On average, respondents had spent thirteen years in vocational ministry. All but one participant was an ordained elder in the UMC (the remaining participant was in the process of becoming ordained and already serving a congregation). Twenty-one respondents were appointed to serve a single congregation, while five respondents pastored multiple churches. Compared to the population of UMC clergy in North Carolina, the sample had more female participants and was slightly younger, but was generally representative of the racial make-up of UMC clergy in North Carolina (90\% of clergy in the state are white, $34 \%$ are women, and the average age is 53 years old, Clergy Health Initiative 2020). Of the 32 congregations served by pastors in our sample, we classified $31 \%$ as being located in rural areas of North Carolina, in accordance with the Rural-Urban Commuting Area Codes of the USDA (USDA Economic Research Service 2020). Additionally, we classified 53\% as small congregations, meaning they had 100 or fewer regularly attending adult parishioners.

All participants provided informed consent prior to the interview. Interviewers, both of whom identified as women and white, were trained in qualitative interviewing and were not affiliated with the UMC. Interviews, which lasted between 50 and $75 \mathrm{~min}$ (mean $=63 \mathrm{~min}$ ), were conducted by Zoom or telephone and audiorecorded. All interviews followed a standard guide that included ten open-ended questions (plus potential guided probes) about how COVID-19 impacted pastors' ministry, how church finances were affected, what stressors pastors faced, and what resources they relied on during this period (see the online supplement for full interview guide). Interviews were transcribed and identifying information removed prior to analysis. Pseudonyms are used to protect participants' confidentiality. Participants received a \$25 incentive for participation. All study procedures were approved by Duke University's Institutional Review Board.

Transcripts were coded in NVivo 12 using applied thematic analysis approaches (Guest et al. 2011; QSR International 1999). First, a structural codebook was deductively developed based on the interview guide and applied to the transcript 
text. In this initial round, codes reflected key topical areas covered in the interview guide-such as changes in ministry, challenges, supports, and congregational finances. For six transcripts (23\%), project analysts met to discuss code applications and refine the structural codebook. Codebook definitions and codes were revised on an as-needed basis by mutual agreement with initial emergent and inductive codes that cut across topical areas added through team discussion. Once coders established general consensus on the codebook and the application of codes, the remaining transcripts were split among three analysts for individual coding. Throughout the structural coding process, analysts created respondent-level and cross-case memos (Deterding and Waters 2018), in which they identified emergent themes, questions, and foci for further analysis. A second round of thematic coding was then conducted in topical areas most relevant to the impacts of COVID-19 on pastoral ministry and congregational culture. To do so, analysts reviewed all text coded as relevant to a given topic (e.g., changes in ministry) and inductively generated a thematic codebook based on common themes in pastors' responses. Thematic codebooks were refined through collective discussion prior to application and then applied to all transcripts by a single analyst to ensure consistency.

This approach to qualitative analysis combines deductive (structured coding) and inductive (thematic coding) approaches to coding-a method best suited to semistructured interview data (Deterding and Waters 2018). The key themes identified in this paper, therefore, reflect respondents' answers to explicit questions as well as their unprompted, spontaneous responses. For example, while we asked pastors explicitly what opportunities the pandemic had created for their congregation, as well as what aspects of their ministry during COVID they were proud of and would like to carry forward, we did not ask pastors to discuss how the pandemic was shaping the meanings of worship or of the Church, more broadly. In addition, pastors often referenced or discussed "silver linings" related to the pandemic spontaneously in other parts of the interview. In each section, the themes highlighted reflect both structured and spontaneous responses.

\section{Findings}

Early in our analysis, we identified resonance between pastors' descriptions of ministry in the wake of COVID-19 and Ann Swidler's conceptualization of "unsettled cultural periods" (Swidler 1986, 2013). As a result, we use this framework to organize and interpret the findings. First, we demonstrate that pastors experienced the early period of the pandemic as an unsettled time, one which disrupted habitual practices and routines, raising the work of ministry to the level of explicit reflection. Second, we describe how pastors were "re-doing" ministry in three key areas-worship, pastoral care, and pastoral identity. In these sections, we build on a key insight from Swidler's (1986) work-that during unsettled periods, people do not construct new strategies of action from scratch. Rather, they assemble existing strategies and practices in new ways to fit the new context (Gross 2009). Notably, however, we found that "redoing" ministry was easier and more effective in some areas (worship) than others (pastoral care). In the final section, we focus on the "silver linings" 
(opportunities) pastors described as a result of the pandemic, drawing attention to the ways in which COVID-19 is beginning to unsettle existing ways of thinking about ministry and the Church.

\section{Unsettling Ministry: The Disruptive Power of COVID-19}

Pastors' descriptions of the pandemic clearly marked this period as an unsettled cultural period. As Swidler (1986, 2013) has argued, unsettled times are ontologically insecure moments when social and cultural norms are in flux. These moments are marked by experiences of uncertainty regarding the future of social institutions and structures within which social practices take form and are given meaning. In such periods, Swidler argues, people find that their cultural "tool kits"-socially-situated and culturally-derived sets of symbols, stories, rituals, and strategies of action, which people use to solve problems-no longer work and require "retooling" (Swidler 1986: 283). In our conversations with pastors, the unsettling effect of the pandemic was evident through the disruption of routines, habits, and rhythms related to ministry, feelings of uncertainty and ambiguity, and the explicit reconsideration of practices that were once taken-for-granted.

The pastors we spoke with described the changes to ministry in the wake of COVID-19 as global in nature. Beverly, for example, told us, "[Ministry] is radically changed. It is absolutely radically changed." Describing the unprecedented nature of the times, Luke reflected,

We're trying to figure it out, but there's no blueprint for this ... It's almost as if all of us now are kind of required to be church planters, to think outside the box, to imagine what it looks like. And for those of us who grew up in the church and have this image of what ministry looks like, to pull yourself apart from that image ... We're unlearning ministry and starting from scratch.

Pastors often resorted to metaphors and analogies that highlighted the newness of the situation they found themselves in - like that of "church planting" — and captured the feeling of being disoriented. Beverly noted, "It's like you've been thrown into the deep end and you better learn how to swim really quickly." Alice told us she felt like they were "reinventing the wheel;" Rebecca remarked she and her staff were "trying to build a plane while we fly it." Prior to COVID, in-person gatherings were a primary means of doing ministry; under COVID, pastors could no longer do "the normal things" they used to do. Many pastors found this overwhelming. As one later-career elder, Alice, told us, "Everything I learned about how to be a pastor, I've virtually had to re-figure out ... I was at a point where I felt completely competent in how to be a pastor and now I no longer feel competent."

Pastors also described this period as one characterized by uncertainty and ambiguity, where there were no clear rules and very little explicit guidance about how to do ministry effectively. Steven told us,

The pandemic has forced us ... into a place where there are no rules, there is no tone. Everybody's trying to figure it out. Everybody's got a slightly differ- 
ent way of doing it. There is no magic pill. Each solution, I think, is congregationally specific ... We're all navigating this in different ways.

Pastors, like Chris, felt they were simply "making this up as we go." Time and again, pastors described the early period of the pandemic as "chaotic" and "frenzied," characterized by trial and error and often riddled with failures. Pastors struggled to quickly create new practices and strategies for doing ministry. Many felt they were left to "figure it out" on their own, with little explicit guidance from denominational authorities.

As a result of the pandemic, pastors could no longer take the "how-to's" of ministry for granted. Steven told us that before COVID, "you just kind of had a routine," but in the wake of COVID-related restrictions, everything became the focus of conscious thought and deliberation. Without routine practices or explicit guidelines to fall back on, pastors deliberated and decided how best to do the work of ministry in ways that were both safe and satisfying for congregants. As Sarah told us, "I think there was a season where it felt like, it was just all figuring out what to do. So much energy, space, and time where it was problem solving and decision making, and navigating decision-making with leaders." When asked directly about their initial experiences, pastors described this period as marked by questions, meetings and discussions-with pastoral teams, lay leaders, and denominational leaders-about how best to move forward. Pastors felt their lives became busier in this early period, not necessarily because there was more to do, but because their established routines were profoundly disrupted and they had to create and implement new forms of practice.

\section{(Re)Doing Ministry in Unsettled Times: Building New Strategies for Congregational Leadership}

If pastoral ministry is, as Luke described it, primarily "the ministry of presence," pastors like Luke were left asking, "How do you remain present when you are not physically present?" In this section, we outline how pastors reported redoing ministry in response to the COVID-19 pandemic and its associated restriction. We ask: What challenges did pastors face? What strategies of action did they implement? As we know from prior research, pastors spend the largest amounts of their time on sermon preparation, administration, visitation, and pastoral care (DeShon 2010; Lehman 1993). Because the pandemic restricted in-person gatherings, it is not surprising that participants named worship services and pastoral care as the areas of their work most dramatically impacted. Pastors also, however, reported changes in how they (and their congregants) understood their role as pastor. We cover each area in turn.

\section{Worship Services}

Figuring out how to conduct worship services online was the most immediate and pressing issue pastors faced as a result of the COVID-19 pandemic. When the order came on Thursday, March 12th, 2020 from the North Carolina bishops 
of the UMC urging pastors to suspend in-person services, pastors had just three days to move worship online or be forced to cancel services entirely (UMC NC Conference 2020a). The first few weeks were described as frenzied, chaotic, and exhausting. It was a period defined by trial and error, especially in relation to technology. For example, Steven described the initial experience as follows,

We decided that doing worship services via Facebook Live was the most logical progression for us to do. But, nobody knew how to do Facebook Live. We knew about it, and I thought I knew what was going on ... I thought all you did was hit the start button. But, no ... After trying to figure out for 20 minutes ... and not having any success, [I] ran back to the office, grabbed the phone, called a member that I knew did Facebook Live, and I said, "Help." She helped me figure out a way to do it, which wasn't exactly the best way to do it, but it worked. About 30 minutes after we were supposed to start the service, our first Facebook Live service started.

Steven was not alone. We repeatedly heard stories of missteps and failed attempts in those early weeks-from slow-downs with Facebook Live to the sound not working or videos taking 12 hours to upload. There were questions about broadcast licenses for music and platform subscriptions to address, equipment to be purchased, and video editing software learned. As Christina told us, "It was kind of crazy. Learned a lot." Eventually, most pastors reported finding a format that worked for their congregations. Steven, for example, reported that he has used Facebook Live "ever since" and feels that the platform "works well for us." Rusty told us, after the first few weeks, "You started to see a break in the clouds, so to speak. You got used to it."

Some pastors had an easier time with technology than others. While solo pastors had to figure out technology on their own or were forced to rely on lay volunteers for assistance, those on pastoral teams often had staff members or associate pastors whose primary job was to manage technology. Unsurprisingly, younger pastors tended to report fewer issues navigating the shift to online worship. As Kathryn, a 26-year-old pastor told us: "Yeah. I'm a millennial and so I didn't have a super hard time with it." Likewise, congregations that were already offering online or streaming services pre-COVID were better-positioned to quickly and easily make the shift online.

Generally, using technology to mediate worship was the most challenging for pastors in rural congregations, where members sometimes lacked reliable internet access, and in churches with older congregants who were unfamiliar or uncomfortable with new technologies like Zoom and Facebook Live. Pastors of these congregations developed creative solutions. One pastor sent CD copies of the worship service to congregants without internet access. Another created a "scripted worship-from-home experience" for congregants each week. In other cases, congregants themselves found creative ways to navigate access-related issues. One of Rusty's congregants who lacked internet access, for example, would call another member who would "hold the phone up to her tablet, and [the woman] listens to the service while the other lady is watching it on her tablet." In each case, pastors and congregants drew on existing knowledge and available 
resources to overcome issues related to access and find ways to stay connected despite existing constraints and limitations.

After pastors had settled on a platform and navigated issues of access, other challenges more inherent to the online format emerged. Twelve of the pastors we spoke with (46\%) lamented the inability to perform practices, like singing and communion, they considered essential elements of the Christian worship experience. For some, like Joe, these constraints led them to question what worship is and what it means,

One of the things that they had said about the pandemic is that we should avoid singing. Well okay, that's reasonable. I get that, but at some point, we're going to need to reflect on what does it mean to be a Christian community that doesn't sing? It's all well and good to say we need alternatives for the passing of the peace, but can we, as a Christian community, give up passing of the peace? What does that mean for us? What changes when you do that?

These aspects of worship felt so central that some pastors were unwilling to skip them and, instead, tried to find creative ways to do them safely. Arthur, whose congregation was meeting outdoors, shared, "I told folks a couple of weeks ago, if you can sing softly, then do so. If you're like me and you can't sing softly, you have to belt it out, then put a mask on so it doesn't spray everywhere." Other pastors continued to include live music in their outdoor services, albeit in pared back forms. Some placed vocalists and musicians fifteen feet away or even inside the chapel, with the sound projected outside.

Communion was also difficult to replicate online. Rebecca told us that she felt the existing substitutes-using "little pre-sealed packs" or "telling people to bring their own elements to an online service"-were not sufficient. For her, "there's something about physically offering the bread and cup" that defined the practice. Rebecca planned a different work-around: her congregants were going to "meet in small groups every now and then on a porch, socially distanced, for $15 \mathrm{~min}$ so that we can have communion." These examples show that the pandemic pushed pastors to consider what parts of worship were essential and which could be dropped or modified, as well as what modifications were acceptable. Pastors were not starting from scratch or trying to reinvent worship; rather, they aimed to maintain its core defining elements but accomplish them in new ways, under the constraints associated with COVID-19.

A final challenge commonly mentioned by pastors was the lack of feedback and interaction with congregants while preaching. Seven of the pastors we spoke with (27\%) mentioned this. Wade told us,

I don't get the feedback that I need to know whether or not what I'm communicating is effective .... If I throw a joke into my sermon, no one ever laughs, no one ever smiles .... I don't get that immediate feedback after the service: "Oh wow. That really made me think about something in a different way" or "That was so comforting." 
This was particularly challenging for pastors who saw preaching as an important part of their pastoral identity. One pastor we spoke with, Margaret, offered a creative solution to this challenge. One of her staff members "will be behind the camera, and their job is to do this [nods her head]. You know? To give the head nod. To say, 'Mm-hmm.' To give an, 'Amen.' To be that physical presence of connectivity." Margaret and her team also took the time before worship to mentally "fill the pews" by naming specific people in the process: "Today, I see Jim and Sarah in the choir loft, and I see David and his children in the balcony." This imaginative exercise helped her feel more connected to her congregation.

As the restrictions and limitations imposed by COVID-19 stretched out, pastors began to think about how to hold worship services (safely) in-person. Fifteen pastors in our sample $(58 \%)$ either had done, were doing, or planned to start outdoor or drive-in services. Of these, four planned to conduct their first outdoor service the week of the interview or had just recently begun doing so, and the remainder reported using outdoor services regularly. While congregants appreciated the chance to gather in-person, even if distanced, pastors reported that outdoor services presented other challenges including those related to sound, space, and high temperatures. Eight pastors (31\%) had or planned to return soon to indoor services at the time of the interview. Pastors who had already returned to in-person services described taking extra precautions: reducing capacity, requiring masks, and/or mandating social distancing by closing off pews. Those who had plans to return in-person soon expressed concerns and anxiety around doing so. As Betsy told us,

I'm not feeling super confident that folks will actually social distance .... I've actually been a little hesitant to even feel like it's a good idea ... but I know that people are really longing to see one another. I understand why we're doing it, but it still feels like, 'Is this the best idea?'

As Betsy's concerns make clear, pastors faced a difficult challenge during this period: they were tasked with finding ways to hold worship services that were meaningful and satisfying-for themselves and their congregants-while also ensuring the safety of their members and abiding by public health guidelines. To do so, pastors did not start from scratch or fundamentally rethink the nature of worship, but rather aimed to maintain and creatively rework foundational aspects of worship-such as singing, communion, and preacher-congregant interaction-in ways that fit the new context and constraints.

\section{Pastoral Care}

While conducting worship services during COVID-19 presented a serious challenge for all of the pastors we spoke with, many identified pastoral care as the aspect of pastoral ministry most disrupted by the pandemic. Pastors told us that pastoral care required physical co-presence and as a result, it could not be effectively redone under the health restrictions. For example, in relation to pastoral care, Luke reflected, "I still would rather do it in person. I just think that there's something really important about human touch, human interaction, that can't quite be fulfilled 
when we're just on technology in our own spheres." Another pastor, Margaret reported,

I had not thought through how much of our work is in person with people, how much of our work is not just listening but holding a hand. Not just praying but hugging ... that pastoral piece has been significantly changed in ways that have been difficult for those we serve, but also for us as pastors.

Unlike worship, where most pastors anticipated maintaining some form of virtual presence post-pandemic, most told us that they would be glad to see "digitally distanced pastoral care ... go away."

Many pastors, in speaking about pastoral care, focused on what they were unable to do during the pandemic; these deficits were more salient than what they were doing to re-configure pastoral care. Fourteen of the twenty-six pastors we spoke with (54\%) mentioned their inability to visit congregants who were sick or isolated, to conduct funerals, and to comfort grieving family members as foundational changes to their ministry under COVID-19 restrictions. Danny told us,

We've had two elderly members of our church actually die of COVID. And they were alone in the hospital. And that's just really hard when you're used to providing care in a certain way in a certain level and the best you can do now is a phone call or a card, which is good, but it's not what it was.

Others lamented being unable to visit home-bound, elderly congregants, as Beverly put it, "to sit at their kitchen table and serve them communion." Pastoral care was deeply tied to pastors' sense of identity and their understanding of what it meant to be a pastor. The practices and actions of caregiving defined the role of "pastor" for themselves and for members of their community. As one pastor, Harry, told us: "I haven't been in the hospital since March and that's a basic part of who I am in caring for the congregation." The inability to fulfill such an important part of their calling has taken a significant emotional toll. Pastors expressed deep sadness about their inability to be (physically) present for congregants during this period.

So, what did pastors report doing to connect with congregants during the pandemic? The most common approaches to pastoral care mentioned in the interviews were telephone calls $(20,78 \%)$, emails and/or text messages $(8,31 \%)$, socially distanced porch or drive-way visits $(7,27 \%)$, and physically mailing letters or cards $(5,19 \%)$. Most pastors used some combination of these approaches to connect with congregants and hoped, as in Fred's words, "that this patchwork would somehow feel like we're in ministry together."

Pastoral care was experienced by some pastors as more stressful and time-consuming during this period. Several reported an increased demand for pastoral care as a result of the pandemic. Many congregants were experiencing anxiety, loneliness, and depression. Older congregants, for whom congregational participation was a primary source of social interaction, were stuck at home. As Kathryn told us, "I feel like there is more to do. There's more pastoral care need." Another 
pastor, Joe told us, "I am more aware of the burden of pastoral ministry." At the same time, however, pastors reported feeling disconnected from their congregants and unaware of their needs. In Rebecca's words, "everything has felt arm's length" since the pandemic began. Pre-COVID, pastors (15\%) reported using weekly services as a means to check-in on congregants and to identify members who were struggling. Without this, pastors worried that congregants may, as Wade put it, "fall through the cracks." Sam told us that pastoral care,

... was easier to do more naturally when we were meeting in-person, because you would be in worship with people and somebody would say, "Oh, well, have you heard about so-and-so?" Or like, "This is what's going on" and you can make those connections naturally ... now it takes a degree of intentionality to do the same thing, and you still feel like you're missing things.

Three other pastors also mentioned the need to be more intentional about pastoral ministry, rather than relying on, as Tom described them, "impromptu connections" during in-person services. Pastoral care under COVID required pastors not only to take more proactive steps to reach out to people, but also more time and effort. As Sam told us, "You have to do a lot more legwork in terms of phone calls to people."

Reaching out to every congregant directly was difficult and, in many cases, impossible, especially for pastors serving large congregations. Eleven pastors we spoke with (42\%) mentioned implementing some form of lay-led and/or congregant-to-congregant contact to better and more sustainably meet the demands of pastoral care. Some pastors used existing groups (e.g., congregational care teams or lay leaders) in new ways. As Christina related, these groups simply "shifted their focus to reaching out." In other cases, pastors created new groups and systems. Margaret told us,

We, from week one, created Pew Pals. We asked people to sign up and then if they said yes, we gave them another congregation member and said, "We want you to once a week ... call them, text them, send them a card." So, empowering the congregation to connect and be pastoral with one another ... My job isn't to do it all. My job is to empower the gifts and strengths of the congregation.

Several pastors, like Margaret, interpreted the need to outsource pastoral care to congregants as a virtue-the pandemic laid bare the fact that pastoral care and community-building should not fall entirely on the shoulders of pastors. As Jane reflected, "It's not sustainable." Instead, they argued, lay people should be actively engaged in creating and maintaining a sense of community. This revelation was the one silver lining mentioned by pastors in relation to pastoral care.

Generally speaking, pastors found pastoral care during the COVID-19 pandemic overwhelming and exhausting. Unable to rely on pre-existing methods and practices for connecting with congregants (namely during worship and through 
in-person visits), pastors were forced to find new ways to do so-most commonly by phone, email, or text. Despite considerable time and effort, however, many still felt that they were not doing enough. As Rebecca told us: "It doesn't feel good enough. It doesn't feel like what we think we need church to feel like." Others, like Jessica, still worried: "Am I getting everybody? Am I getting the people who want to be gotten?" None of the pastors we spoke with felt satisfied with their ability to do pastoral care during the pandemic.

\section{Role of the Pastor}

Eighteen of our participants $(69 \%)$ described salient changes in the pastoral role during the pandemic. Pre-COVID, preaching and pastoral care marked the pastors' role as shepherds of their flocks. As Christina shared, leading "Sunday morning worship in a building, that is so much what we are. That is what I do. That is what I lead. That's what I plan most of my time around is this worshipful event." For pastors like Christina, leading in-person worship services and doing pastoral care are "what [pastors] are" and "what [pastors] do." The inability to perform these tasks in familiar ways forced a renegotiation of pastoral identity.

At the same time, we found that the pandemic introduced new pastoral duties. For half of our respondents (13 out of 26), a novel pastoral role emerged in the context of COVID-19- the role of interpreting public health information for their parishioners. Seemingly by necessity as opposed to by choice, in a time of confusing and often contradictory information, congregants turned to their pastors as an authoritative voice on how to safely negotiate the health risks of COVID-19. Arthur represented this trend. Reflecting on the shifting information and guidance around masking early in the pandemic, Arthur reported,

My people are, "Pastor, what do we do?" Okay, and it now falls on me to try to come up with the best answer. They talk about, "Well, the virus lives on surfaces for days. No, wait, it doesn't live on surfaces for very long, but then again it might, so you probably shouldn't touch anything." It's been that all along with COVID ... I'm getting a lot of people looking to me... They're looking to me for leadership and wisdom, and I'm having to do a whole lot of studying to try to figure it out for them.

For our respondents, the weightiest part of serving as an interpreter of public health was making the decision of whether and how to meet safely for in-person worship. Reflecting on the decision to resume in-person worship services, Christina said, "I just felt like the burden was on me to make sure it was right. Morally, because you don't want people to die." However, pastors also saw this newfound responsibility as interpreters of public health information as a natural outflowing of their pastoral role. Harry stated, "I am very strong on helping us to wear a mask, social distancing, following the best science, staying home when you can ... That's a big thing, part of my responsibility." Pastors understood their role as health interpreters to be a part of their responsibility as pastors, however far outside of their training or the traditional conception of the pastoral role. 
Additionally, thirteen of the pastors interviewed (50\%) emphasized that their role in the context of COVID-19 was one of providing stability and comfort in the midst of an unsettling time. Kathryn reported that her role is "to care for people as well as I can." She continued,

What people need right now is to receive hope, to receive care ... to feel like they have some sort of community and stability in a time where there's not a lot of stability ... helping to facilitate and provide those things sort of feels like the most important part of my job right now.

Kathryn identified her role as offering stability and hope. Other pastors discussed "allaying people's fears" (Joe), "being a less anxious presence" (Alice), "model[ing] that non-anxious space" (Sarah), and "being a calming influence" (Rusty). In the unsettled times of COVID, remaining a constant, stable, and calm presence appears to have emerged as a core to many pastor's identities. This echoes similar findings about how pastoral identity is renegotiated during natural disasters (Bradfield et al. 1989; Hirono and Blake 2017; Molteni et al. 2020).

Even though traditional tasks associated with the pastoral role-preaching and pastoral care-were diminished in the early period of the pandemic, the importance of the pastoral identity remained constant. As Alice stated, "I suppose the role itself hasn't changed, so maybe that's the wrong terminology, but the way I implement moving into that role is completely different." Similarly, another pastor, Tom, reflected, "My pastoral roles have shifted, but I don't think my identity has changed. I am still a pastor." The pastors we interviewed were engaged in renegotiating their professional identities to face the difficulties of leading a congregation during a pandemic. As a result, the central pastoral tasks appeared to have shifted from preaching and counseling to interpreting and comforting. These changes, however, were interpreted in relation to the pastors' over-arching role as shepherd of their flock and did not, for most of the pastors we spoke with, more fundamentally unsettle their pastoral identity.

\section{Silver Linings in Unsettled Times}

Despite the challenges presented by this unsettled period, some pastors welcomed the disruption to pre-existing routines and rhythms because it opened up space to start "new traditions." By unsettling ministry-as-usual, the pandemic allowed pastors to reimagine and creatively re-work different aspects of ministry. Some pastors even described this period as energizing and exciting. Others told us that the disruptions were associated with a "richer feeling" to their work and to faith life. These pastors felt the current moment presented opportunities for their congregations and the Christian church, more broadly. As Jessica told us: "It's definitely been hard ... but I feel like this pandemic has done a lot for our church." Luke said, "The season that we're in, it's heartbreaking, but it's also exciting." Many of the pastors we spoke with were able to identify some silver linings around the 
hardships of the pandemic: positive impacts of this period and/or changes in practice they hoped to carry forward.

Most notably, many pastors saw benefits to being forced online, even though the initial move was challenging. Eighteen of the pastors with spoke with (69\%) reported reaching a wider audience through virtual services and online Bible study. As Wade told us, "Our reach is now much, much larger. We're not only reaching people in the [local] area. I've got people from former churches, friends, and family members ... you can do that now." While pastors found it hard to gauge exactly how many people attended worship online- How many people are behind each "participant"? Is every viewer actually engaged? most believed they were reaching more people now than pre-COVID. Others appreciated that the pandemic forced them to do things, like create or revamp the church website and buy updated electronics that "needed to happen anyway." As Mary told us: "For years, I thought, 'Hey, we need to go live stream' ... There's nothing like necessity, right? ... We have actually stepped into a realm that we needed to step into a long time ago." Most of the pastors we spoke with anticipated continuing these practices, including online worship and virtual Bible study meetings, post-COVID.

Many pastors also appreciated the opportunity to creatively re-think the structure and content of worship services. For pastors like Beverly, "getting [out] of the comfort zone of worship" was "a blessing in disguise." Luke, who used the metaphor of "church planting" to describe the pandemic's impact on ministry in the section above, told us,

The part from technology that I hope we don't lose, that I do want to carry, is that creativity. Worship can be stale ... There was just a new breath that was added when we were able to lean into the creative aspect of our worship. We've always lived with this fourfold pattern of worship, which I recognize as just deep roots in the history of Christianity ... but I do think that we are in this level of creativity, of just going back to the whiteboard and saying, "We're back in the beginning ... We're all trying to think outside the box about how we can do ministry differently."

Luke was not alone in embracing the creative opportunities of online worship. Pastors shared a range of ways in which they were modifying pre-existing practices. At Betsy's congregation, the pastors began to offer services that were "teampreached as a conversation." Each week, one pastor takes the lead but "then the secondary preacher jumps in with illustrations and other thoughts." Betsy found this new style of worship so enriching and enjoyable that she lamented having to return to the old way of doing things post-COVID. Chris told us that while usually he would wear a suit and tie to preach, in "the Corona church," he wore "blue jeans and button ups," preached while "seated on bar stools" and "talk[ed] directly into the iPhone." Another, Rebecca, encouraged her congregants to implement their own personal rituals to create a feeling of sacred space: "We encourage people to set up worship stations with a candle ... that's a piece of that morning ritual, to stop and to take a breath and to light your candle." In each of these ways, 
the pandemic offered pastors opportunities to experiment with new forms, styles, and practices of worship.

At the same time, however, pastors also expressed a desire to maintain certain core elements of worship and of their congregation's particular style. As mentioned above, for many, maintaining definitive practices such as singing and communion was essential. Others insisted on finding an online platform that fit their congregation's unique worship style. Christina, for example, noted,

We've really tried to retain who we are. So, in worship, we really focused on participatory worship and connection. We did that when we were in person ... We talk to each other, we eat food, we do prayer practice, we gather in small groups and talk .... We really tried to bring that into online and retain the same things. So, in a different medium, but same principles guiding us.

Like Christina, Margaret told us she was "proud of the ways we have continued to be who we are, even as we've pivoted to the virtual." For many pastors, the work of re-doing worship services in the wake of COVID-19 involved walking a fine line between creatively reimagining worship and maintaining its foundational and familiar elements. To do so, pastors drew on existing resources and cultural styles but also created new practices to meet the challenges of doing worship under the requirements of social distancing.

Most of the silver linings pastors described in relation to the pandemic were practical in nature - new ways of doing ministry or worship - rather than a more fundamental re-thinking of the meanings or goals of ministry, the church, or of their faith-something echoed in the literature on religious leaders' responses to natural disasters (Ghiloni and Shaw 2013). However, there were some pastors, like Danny, who saw the pandemic as leading to changes at a more "theoretical, big picture level." As Beverly told us, "I think we've all been knocked off our center as far as how we define Christianity and what it means to walk with Jesus and then continue to press forward to what does it mean on a day-to-day basis?" These pastors saw the pandemic as a "new day" for the church and felt that they could not go back to the old routines and habits. As Beverly, told us, "You've got to keep your eyes on the arc because this is new territory. I mean, the whole thing about going into the sanctuary, we're not going back into the sanctuary, we're entering into the sanctuary in a completely different way." Carolyn reflected, "Pandora's box has been opened ... We're going to have to think about church differently." While most pastors did not concretely describe what this new reality would look like, we saw some evidence that the pandemic was beginning to unsettle taken-for-granted understandings of "the Church."

Eleven of the pastors we spoke with (42\%) felt that the pandemic was teaching Christians, or at least reminding them that, as Carolyn said, "the church is not the building." This was echoed by Danny,

I think a lot of this is ... forcing people-pastors and clergy and laypeople alike-to really think deeply about their ecclesiology, about how they understand the church. So often people ... when they say church, what they 
mean is a Sunday morning worship service, "I'm going to church," or they think church as the physical structure where Christians gather.

While many pastors felt they already believed this conceptually, the pandemic forced pastors and their congregants to live into this reality. For these pastors, this was a silver lining in an otherwise disorienting time. Margaret spoke of the sense the walls of the church "were hindering our ministry," and pastors, like Jane, were proud to become less "building-centric."

For some of the pastors we spoke with, this rethinking of the Church-as more than the physical building-corresponded with a prioritization of communityoriented ministry. For example, Jane told us that thinking about "the church as beyond just the building" implied "thinking of the ministries of the church not as focused on serving ourselves, but outward-focused." Luke reflected,

It is fascinating to see us take on this external-facing presence as opposed to the internal gathering presence that we once were so focused on. So, there's part of me that, while it's painful to not have the ministry presence with the congregation ... I'm actually very proud of our congregation for being so present to the external-facing community, and to start looking outward as opposed to inward.

For these pastors, the pandemic represented an opportunity-and in some cases, an important push — to reorient their ministry outward, towards the community. Most pastors already held this as something they cared about and valued. The pandemic pushed them to more fully align their practices with their values.

For others, thinking of the Church as more than a building was associated with shifting views of whether and how laypeople should be involved in their own spiritual formation. The practical realities of COVID-19 created circumstances in which congregants could no longer depend on the pastor and/or on weekly services as the main pillars of their faith life. Instead, the pandemic forced congregants, as Christian put it, to "pick up a spoon" and become more agentic in their spiritual growth-rather than be "spoon fed" by pastors. Jessica told us that during COVID, she has encouraged congregants "to take more responsibility for their own spiritual growth rather than simply having programs or things they come to that we facilitate." Another pastor, Jane, told us, "We're seeing ourselves as equipping people to be their own disciples, to be less reliant on us to give them what they need." Without in-person, weekly services, pastors and congregants were rethinking the foundations of religious and spiritual life. While this change was rooted in pandemic-related restrictions, some pastors saw this as a valuable shift, one that aligned with their pre-existing valuesas Christina related, "I think I've always had that value, and it's always been something that I cared about" - and which they hoped to carry forward. These responses then point towards potentially longer-lasting implications of the pandemic for pastoral ministry and congregational culture. 


\section{Discussion}

In this paper, we used in-depth, semi-structured interviews with UMC clergy to provide a detailed picture of how pastors and congregations experienced and responded to the restrictions associated with COVID-19 during the early stages of the pandemic. This study has several important conclusions for future research regarding COVID-19's impact on religious life. First and most broadly is the value of examining the pandemic as an unsettled cultural period (Swidler 1986, 2013) for religious institutions and religious leaders. Our findings suggest that this framework fits well with how pastors experienced the pandemic. Moreover, Swidler's framework directs our attention in useful ways and raises important questions about the impact of COVID on both pastoral ministry and congregational culture in the short and longer term.

For example, while major events such as the COVID-19 pandemic are often described, especially in retrospect, as watershed moments, Swidler's framework and our findings encourage us to be wary, or at least a bit skeptical, of this framing. In this study, we documented pastors in the middle of an unsettled cultural period negotiating and creating new strategies of action for pastoral ministry. To do so, pastors borrowed bits and pieces of cultural and technological resources from their existing toolkits to assemble new practices that fit the constraints and regulations that defined this period. Pastors, for example, sought to maintain core elements of pre-existing practices such as singing and communion in worship as well as human touch and connection in pastoral care. In fact, the pandemic made the essentialness of these aspects of practice more explicit. Pastors also sought to align new forms of practice with their congregation's pre-existing cultural style, and changes in practice were justified and interpreted through pre-existing cultural frameworks and values. While the pandemic pushed pastors and congregants to re-think "the Church" as more than a building, this shift was discursively rooted in Biblical texts and framed as aligning with pastors' core values. These findings all suggest that "unsettled times" are characterized by conscious efforts to match new practices and strategies of action with pre-existing ideas, values, and resources, while also being responsive to the changing context. Future research should attend to how religious producers are navigating this tension in the latter stages of the pandemic and beyond.

Swidler's framework also draws attention to both practical and ideological change during unsettled times, and to the dynamic interplay between these related but analytically distinct forms of change. In our interviews, pastors were more focused on the practical changes to ministry (i.e., the hows of ministry) than on the "theoretical, big picture" implications of the pandemic (i.e., the whys of ministry). This finding, however, may reflect the timing of our interviews, which occurred relatively early in this unsettled cultural period. As others have argued, nascent ideologies tend to be "reactionary in nature - always lagging several years behind the "unsettling' events" (Regnerus and Smith 1998: 1352). It is possible that more ideological shifts will begin to emerge as the long tail of the pandemic starts to disrupt taken-for-granted meanings and priorities. As outlined 
above, we saw some evidence of ideological shifts among pastors who were rethinking the nature of ministry and the meaning and goals of the Church. The pandemic, for example, raised questions about what responsibilities-such as community-building and personal spiritual formation-should fall to the pastor alone or be shared among congregants. Future research should attend to changes in both religious practice (strategies of action) and ideology (discourses and meanings) as the pandemic unfolds as well as the interplay between them. Swidler's (1986) work focused primarily on periods of major ideological disruption, which she argued often required and enabled changes in practice. The pandemic, however, in its initial phases, fundamentally disrupted taken-for-granted practices, which may or may not have longer-term implications for religious ideologies and institutional systems.

Finally, Swidler's framework draws our attention to the potential role of pastors, congregations, and religious institutions as sources of stability (or 'settledness') during unsettled cultural periods such as pandemics and natural disasters (Bradfield et al 1989; Ghiloni and Shwa 2013; Hironi and Blake 2017). We found that providing a sense of comfort and stability emerged as an important aspect of the pastoral role during COVID-19. Pastors' emphasis on preserving familiar elements of worship and congregational culture may reflect this goal. While the traditionalism and stability associated with congregational life is sometimes perceived to be a liability, it may become an asset during unsettled cultural periods when people are more likely to seek out institutions, communities, and rituals that provide feelings of comfort and familiarity (see Molteni et al 2020). ${ }^{3}$ This suggests that we may see a short-term uptick in religious participation and/or religious practices during the early period of the pandemic.

This research also suggests that pastor demographics (especially, career stage, age, and gender) may shape the experiences and responses of clergy and congregations during the pandemic. Some of the pastors we spoke with were doing welleven thriving-despite the challenges. Others, however, were struggling and, in large part, unable to see any positive aspects of the pandemic. Two of the pastors we spoke with, both later-career women, said they were considering leaving ministry. Alice told us,

I've probably thought more about retirement since this started than I had. Before, I was really committed to going another eight years until mandatory retirement, but this has made me question whether I really want to do that. Because it is just harder. This is a harder job than it normally is.

Unlike some of her fellow pastors, Alice saw more challenges than opportunities. In fact, she felt it was "a little bit Pollyannaish" to focus on positive aspects of the pandemic.

Several key factors seem to play a role in shaping pastors' experiences with and responses to COVID-19. We found that pastors of smaller and/or rural congregations

\footnotetext{
3 We thank an anonymous reviewer for this insight.
} 
faced additional challenges in moving services online (including access issues) than their counterparts in larger and/or urban congregations. Younger and/or early career pastors tended to find it easier to manage this and other transitions, and expressed the most positive views of the pandemic. Early career pastors were more likely to speak of the opportunities to be creative and innovative, while later career pastors, like Alice, more often reported being overwhelmed and exhausted by having to rethink and redo ministry in this new context. ${ }^{4}$ Pastors in the later stages of their careers likely have more deeply ingrained routines and longer-running habits in relation to how they do ministry- "tool kits" (Swidler 1986) that are both more developed and less flexible. We found evidence of similar differences between associate and senior/ solo pastors. All of the associate pastors we spoke with mentioned creativity while only one-third of the lead and solo pastors did. Future research should look closely at how pastors' experiences and responses to the pandemic vary across these lines of difference, among others-including gender, geographic location, denomination, and religious tradition.

This study has several important limitations. First, our findings come from one denomination and do not necessarily generalize to churches from other denominations. By and large, UMC churches in North Carolina sought to abide by state health guidelines. This was not the necessarily the case in other churches (Lifeway Research 2020; Seabright and Raiber 2020). All the pastors we interviewed were in North Carolina, which limits our ability to generalize to other parts of the United States. Our focus on Protestant Christian clergy limits our findings to the experiences of these pastors and do not necessarily generalize to other religious groups (cf. Ebrahim and Memish 2020; Miller et al. 2020). For example, what is considered "core" elements of worship (or of pastoral ministry, more generally) may vary across denominations and traditions. For UMC pastors, the Book of Discipline outlines the responsibilities and duties of an elder to be comprised equally of preaching, counseling, and administering the sacraments, such as baptism and communion (The Book of Discipline of The United Methodist Church 2016). The pastors in our sample renegotiated and reimagined congregational life and their pastoral roles in line with the previously established Methodist customs. If we had interviewed Catholic priests, however, we likely would have heard more respondents discuss distribution of the Eucharist in the context of COVID-19.

Second, not all contacted pastors responded to our invitation to participate in this study. It is possible pastors who were struggling or having a harder time during the pandemic were less likely to respond, suggesting that the picture painted here could be rosier than the reality faced by other pastors. Also, the UMC pastors we spoke to were predominantly white, which may limit the ability to generalize to pastors of other racial and ethnic identities. We attempted to ensure we had voices from pastors of color (BIPOC) to match their population in the denomination, but these pastors were less likely to participate. Of the 35 pastors contacted who did not participate in the study, a third were BIPOC.

\footnotetext{
$480 \%$ of the early career elders, $56 \%$ of the mid-career elders, and just $14 \%$ of the later career elders mentioned creativity as a positive aspect of the pandemic.
} 
Finally, this study provides a snap-shot of pastors' experiences and responses during the early period of the pandemic (June to August 2020). COVID-19, however, was a rapidly unfolding situation and pastors' experiences and responses may have changed and shifted over time. Our research team also conducted an additional 23 interviews with local pastors (i.e., non-ordained clergy) between August, 2020 and December, 2021. In these interviews, pastors related more stories of conflict and division within their congregations over reopening plans. Likewise, while pastors reported finding suitable ways to do ministry at the time of our interviews, these strategies may be less satisfying and less effective in the longer-term. As one pastor, Carolyn, told us: "Initially, you know, that's not a big deal as far as not being able to physically be in the same space [...] To not have that now for four months ... It's palpable." What is missing in the virtual context may become more salient over time.

\section{Conclusion and Implications}

This study provides an in-depth look at how pastors in one denomination experienced and responded to COVID-related restrictions. Broadly, we found that the pandemic unsettled routine and previously taken-for-granted ways of doing ministry. Many pastors experienced this unsettled period as challenging and disruptive. The pandemic forced pastors to quickly learn new skills and take on new roles as they tried to figure out how to do ministry safely and effectively. Creating new practices and strategies of action was time-consuming, mentally taxing, and stressful. At the same time, many of the pastors we spoke with could see and articulate opportunities or silver linings amid the challenges they faced. By unsettling ministry-as-usual, COVID-19 opened up space for pastors to both redo and rethink the practices and, in some cases, the goals of ministry. While pastors were able to be creative as they crafted new forms of practice and strategies of action to meet the restriction, we also saw evidence that pastors aimed to strike a balance between creatively re-doing religious practice, on the one hand, and maintaining core elements of existing rituals and congregational styles, on the other.

This study provides a baseline for investigating similarities and differences in the responses of pastors within and across denominations and traditions. It also provides a baseline for assessing whether and which changes in ministry implemented during the early stages of the pandemic remain in place in the post-COVID world. Will the practices and creative solutions outlined here disappear when the constraints associated with COVID-19 are removed, or will some of these new practices prove "sticky," ultimately expanding the cultural toolkits of pastors and congregations? Existing research on cultural change suggests that new practices become routinized and habituated only when they are recognized as useful solutions to emergent and persistent problems (Gross 2009; Jansen 2016). Will the new strategies pastors implemented during COVID continue to be deemed useful post-pandemic? Will congregations continue to offer online worship experiences after they return to inperson services? Will virtual attendance decline over time? Will pastors continue to rely on congregants for assistance in community-building and pastoral care? Will 
those whose understanding of "the Church" was expanded during COVID continue to look outward, "beyond the walls," or will a more inward-looking focus return when the community is allowed to gather together again, inside the walls of church?

Acknowledgements The authors would like to thank Elizabeth Stringfield for her help conducting the interviews for this project.

Funding This research was supported by a generous grant from the Rural Church Area of The Duke Endowment.

\section{References}

Bradfield, C., M.L. Wylie, and L.G. Echterling. 1989. After the flood: the response of ministers to a natural disaster. Sociology of Religion 49 (4): 397-407. https://doi.org/10.2307/3711225.

Bridges V. 2020. Federal Judge Blocks NC Governor's Restrictions on Religious Services. Raleigh News and Observer.

Chaves, Mark. 2004. Congregations in America. Cambridge, Mass: Harvard University Press.

Chaves, M., M. Hawkins, A. Holleman, and J. Roso. 2020. Introducing the fourth wave of the national congregations study. Journal for the Scientific Study of Religion 59 (4): 646-650.

Clergy Health Initiative. 2020. 2019 Clergy health initiative summary report. Durham, N.C.: Duke University Divinity School.

DeShon, Richard P. 2010. Clergy Effectiveness: National Survey Results. General Board of Higher Education and Ministry: United Methodist Church.

Deterding, N.M., and M.C. Waters. 2018. Flexible coding of in-depth interviews: a twenty-first-century approach. Sociological Methods and Research. https://doi.org/10.1177/0049124118799377.

Ebrahim, S.H., and Z.A. Memish. 2020. Saudi Arabia's drastic measures to curb the COVID-19 outbreak: temporary suspension of the Umrah pilgrimage. Journal of Travel Medicine. https://doi.org/ 10.1093/jtm/taaa029.

General Council on Finance and Administration of the United Methodist Church. 2018. "2018 Annual Conference Membership and Attendance in the US." Retrieved January 27, 2021 (https://www.gcfa. org/media/2132/2018-annual-conference-membership-and-attendance-us.pdf).

Ghiloni, Aaron J., and Sylvie Shaw. 2013. 'Gumboot religion': religious responses to an Australian natural disaster. Journal for the Study of Religion, Nature and Culture 7 (1): 27-48.

Goode, J.P., D.R. Stroup, and E. Gaufman. 2020. Everyday nationalism in unsettled times. In search of normality during pandemic. Nationalities Papers. https://doi.org/10.1017/nps.2020.40.

Gross, Neil. 2009. A pragmatist theory of social mechanisms. American Sociological Review 74 (3): 358-379. https://doi.org/10.1177/000312240907400302.

Guest, G., K.M. MacQueen, and E.E. Namey. 2011. Applied thematic analysis. California: SAGE Publications.

Hirono, T., and M.E. Blake. 2017. The role of religious leaders in the restoration of hope following natural disasters. SAGE Open 7 (2): 2158244017707003.

Jansen, R.S. 2016. Situated political innovation: explaining the historical emergence of new modes of political practice. Theory and Society 45 (4): 319-360. https://doi.org/10.1007/s11186-016-9272-0.

Lehman, E.C. 1993. Gender and work: the case of the clergy. New York: SUNY Press.

Lifeway Research. 2020. Pastors' Views on How COVID-19 Is Affecting Their Church April 2020: Survey of American Protestant Pastors.

Manion, Matthew F. and Alicia Strandberg. 2020. "Covid Parish Impact Study, Summary of Findings." The Center for Church Management, Villanova University. Villanova, Pennsylvania. https:// villanovachurchmanagement.com/wp-content/uploads/2020/12/COVID-19-Parish-Impact-StudySummary-of-Findings.pdf.

Miller, A.C., A.A.C. Bigalli, and P. Sumanam. 2020. The coronavirus disease-2019 pandemic, social distancing, and observance of religious holidays: perspectives from Catholicism, Islam, Judaism, and Hinduism. International Journal of Critical Illness and Injury Science 10 (2): 49-52. https://doi. org/10.4103/IJCIIS.IJCIIS_60_20. 
Molteni, F., R. Ladini, F. Biolcati, A.M. Chiesi, GMDotti. Sani, S. Guglielmi, M. Maraffi, A. Pedrazzani, P. Segatti, and C. Vezzoni. 2020. Searching for comfort in religion: insecurity and religious behaviour during the covid-19 pandemic in Italy. European Societies 0 (0): 1-17. https://doi.org/10.1080/ 14616696.2020.1836383.

O'Brien, Hazel. 2020. "What does the rise of digital religion during Covid-19 tell us about religion's capacity to adapt?" Irish Journal of Sociology 28(2): 242-246.

QSR International. 1999. NVivo qualitative data analysis software. Doncaster: QSR International.

Regnerus, M.D., and C. Smith. 1998. Selective deprivatization among American religious traditions: the reversal of the great reversal* I social forces I Oxford academic. Social Forces 76 (4): 1347-1372.

Seabright, Paul, and Eva Raiber. 2020. "U.S. Churches' Response to COVID-19: Results from Facebook." Center for Economic Policy Research Discussion Paper Series DP15566.

Shepherd, Hana, Norah MacKendrick, and G. Cristina Mora. 2020. Pandemic politics: political worldviews and covid-19 beliefs and practices in an unsettled time. Socius 6: 2378023120972575.

Sulkowski, Lukasz and Grzegorz Ignatowski. 2020. "Impact of COVID-19 pandemic on organization of religious behaviour in different christian denominations in Poland." Religions 11: 254.

Swidler, Ann. 1986. Culture in action: symbols and strategies. American Sociological Review 51 (2): 273-286. https://doi.org/10.2307/2095521.

Swidler, A. 2013. Talk of Love: How Culture Matters. Chicago: University of Chicago Press.

The Book of Discipline of the United Methodist Church. 2016. Nashville, 2016. Tennessee: United Methodist Publishing House.

UMC NC Conference. 2020a. "Bishop Ward Urges Churches to Cease Public Worship for Two Weeks." Coronavirus Response. Retrieved May 6, 2021 (https://nccumc.org/bishop/bishop-ward-urges-churc hes-to-cease-public-worship-for-two-weeks/).

UMC NC Conference. 2020b. "From the Bishop: Model for Renewing Face-to-Face Community \& Worship - Bishop's Office - NC Conference." Bishop's Office. Retrieved May 6, 2021 (https://nccumc. org/bishop/from-the-bishop-model-for-renewing-face-to-face-community-worship/).

UMC Western NC Conference. 2020. "From the WNC Cabinet: Considerations Before Reopening." Retrieved May 6, 2021 (https://www.wnccumc.org/newsdetail/considerations-before-reopening13626851).

USDA Economic Research Service. 2020. Rural-Urban Commuting Area Codes. U.S. Department of Agriculture. https://www.ers.usda.gov/data-products/rural-urban-commuting-area-codes/.

Publisher's Note Springer Nature remains neutral with regard to jurisdictional claims in published maps and institutional affiliations.

\section{Authors and Affiliations}

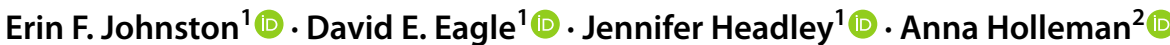

Erin F. Johnston

erin.johnston1@duke.edu

1 Duke Global Health Institute, Duke University, 310 Trent Drive, Durham, NC 27708, USA

2 Department of Sociology, Duke University, Durham, NC, USA 